\title{
RECOMENDAÇÕES PARA QUEM REDIGE UMA PROVA LINGUÍSTICA ${ }^{1}$
}

Paolo Torresan (UFF)

Resumo: Redigir uma prova linguística (seja qual for o conteúdo e a tipologia de exercícios/atividades que ela implica) é uma tarefa complexa, pois exige diferentes habilidades, a saber, o cuidado com os detalhes e o pensamento complexo (ou seja, a possibilidade de levar em consideração diferentes variáveis ao mesmo tempo). No caso deste artigo, consideramos cerca de 100 sugestões que possibilitam o docente ter um olhar atento e crítico durante a elaboração, a aplicação e correção da prova.

Palavras-Chave: Avaliação linguística; item writing; validade de uma prova.

Abstract: Writing a linguistic test (whatever the content and type of exercises / activities it entails) is a complex task, as it requires different skills, namely, care for details and complex thinking (that is, the possibility of take into account different variables at the same time). In the case of this article, we consider about 100 suggestions that enable the teacher to have a careful and critical eye during the preparation, application and correction of the test.

Keywords: linguistic assessment; item writing; validity of a test.

\section{TIPOS DE PROVAS LINGUÍSTICAS}

Muitos cursos de língua são estruturados de tal maneira que, por meio de provas em períodos pré-estabelecidos (por exemplo, na metade e no fim do curso), o docente obtém um indício do progresso da competência do estudante. A partir do resultado, consegue avaliar se o estudante pode passar para o próximo nível ou não.

1 Tradução de Bárbara Cristina Mafra dos Santos (UFSC) e Sergio Romanelli (UFSC). 
Provas deste tipo constituem a síntese de um percurso feito, tem como objetivo componentes linguísticos (léxico e morfologia, in primis) e/ou habilidades tratadas durante o curso. São chamados testes/provas de aproveitamento (achievement test) e se distinguem de provas de outros gêneros ${ }^{2}$, entre estas as mais importantes são:

- A prova de nivelamento ou de ingresso (placement test), que visa classificar os estudantes antes do início do curso, com base nos seus conhecimentos e nas suas competências (de modo a aprová-los para uma turma de nível correspondente);

- A prova de proficiência (proficiency test), elaborada por um centro certificador e abstrata com relação a contextos linguístico-culturais específicos.

A prova de proficiência tem, portanto, uma disposição universal (vale para estudantes provenientes de diversas experiências e que querem servir-se do título por finalidades próprias); já a prova de nivelamento tem natureza local (é elaborada pela própria instituição e é, geralmente, cuidadosamente controlada), enquanto a prova de aproveitamento tem natureza idiossincrática (é elaborada por um grupo específico).

As três provas se somam (funcionam como uma espécie de "amostra" daquilo que o aluno sabe fazer aqui e agora)

2 Cf. Rocca, 2006. 
e estendem as inferências deduzidas ao conhecimento/ competência objeto de juízo³.

Uma prova de proficiência é, em geral, submetida a uma série de processos de validação (formação dos item writer; triangulação dos juízos por parte dos procedimentos equivalentes; aperfeiçoamento da prova através de um ou mais pretesting, etc.) que garantem a esta um alto grau de validade e de credibilidade. Ao contrário, as provas de nivelamento (a menos que não sejam elaboradas por centros especializados) e, acima de tudo, as provas de aproveitamento, são frutos de um trabalho 'artesanal'.

Na melhor das hipóteses, nestes casos, mais professores se confrontam entre si; é quase sempre, porém, um único professor que prepara a prova e a administra, sem o apoio de outros.

Frequentemente a(s) formação(ões) das quais o professor dispõe são relativamente restritas: pode ser que no seu percurso de estudos não tenha enfrentado esta questão; ou, então, pode ter sido instruído em relação a uma série de noções teóricas, mas sem ter tido a possibilidade de desenvolver uma competência neste sentido. Portanto, pode acontecer que, no receio de prosseguir em um

3 Não se exclui que cada uma dessas possa exercer, também, uma função formativa: um estudante que se prepara para uma prova pode, depois de tudo, adquirir estratégias de vários tipos (linguísticas, cognitivas e metacognitivas) para serem exercitadas durante a aprendizagem autônoma. 
terreno no qual se sente despreparado, o professor se serve de exemplos obtidos online; geralmente em provas de proficiência, realizando verdadeiros collage.

De tal forma, o seguinte artigo tem o objetivo de elencar uma série de práticas de monitoramento e de controle, em grande parte voltado àqueles que se ocupam do testing por profissão, os item writer. Seguindo essas práticas, o professor pode se assegurar da qualidade do próprio juízo, implementando uma prova de aproveitamento que tenha uma certa garantia de qualidade.

O quadro pode constituir a base de um protocolo de revisão estendido a todos os três tipos de prova. Aconselhamos o leitor-avaliador a imprimir o artigo e a dar atenção às ações que geralmente passam despercebidas.

\section{RECOMENDAÇÕES}

Toda prova linguística é inevitavelmente imprecisa. As recomendações que compartilhamos tem o objetivo de reduzir tais margens de imprecisão. As dividimos nos seguintes âmbitos:

- recomendações gerais (2.1);

- recomendações específicas (2.2);

- relativas aos componentes linguísticos, em particular gramática e léxico (2.2.1); 
- relativas às habilidades (2.2.2);

- perceptivas (2.2.2.1);

- produtivas (2.2.2.2).

As fontes às quais recorremos são várias (Alderson et al. 1995. Cangelosi, 1990. Green, 2017. Haladyna et al., 2002. Kitsch, Yarbrough, 1982. Novello, 2015. Purpura, 2004. Schedl, Malloy, 2014. Torresan, 2015a, 2015b. Serragiotto, 2016). Algumas recomendações são fruto de uma reflexão pessoal nossa.

\subsection{Recomendações gerais}

A seguir, apresentamos, uma série de sugestões destinadas a qualquer tipo de prova, de qualquer que seja o conteúdo ao qual essa se aplica.

1. Para que seja válida, a avaliação não deve ser "contaminada" a partir de considerações de fatores externos ao objeto de relevância (ex.: em uma prova de compreensão que possui questões abertas, os alunos não podem ser penalizados se as suas respostas possuírem erros gramaticais ou ortográficos);

2. É preciso assegurar-se de que na prova não haja uma fotografia muito parcial daquilo que se pretende relevar (por exemplo, uma avaliação oral que considere apenas a exatidão restitui uma imagem reduzida da habilidade de produção oral); 
3. Pode ser negociado com a turma, caso a instituição permita, o número, a distribuição e a duração das provas e, se for o caso, o tipo de formato, ou seja, o tipo de técnica ou de técnicas;

4. As provas devem ser dimensionadas; não devem ser fáceis demais, subestimadas, nem difíceis demais, superestimadas (há professores que formulam questões enganosas e insidiosas para colocar os alunos à prova, mas até os mais competentes estudantes podem não saber respondê-las);

5. As provas de aproveitamento devem estar inseridas dentro de um programa curricular e devem ser realizadas a fim de verificar o progresso dos alunos (outros usos, como 'a prova surpresa' usada como arma de represália, são eticamente discutíveis);

6. Devem ser consideradas as exigências de alunos com necessidades especiais;

7. O tempo deve ser adequadamente calculado;

8. É recomendável programar uma simulação antes de aplicar a prova (os alunos praticam com exercícios/atividades homólogos); em todo caso, o formato deve ser familiar para o aluno;

9. A prova deve refletir o foco do curso; é inapropriado servir-se de uma prova exclusivamente gramatical se, por exemplo, o foco é comunicativo; 
10. Se possível, a prova deve ser submetida a uma turma de mesmo nível, de modo que possam emergir - e assim serem corrigidas - eventuais imperfeições (tal prática é útil em particular na formulação de provas de compreensão auditiva para níveis iniciantes, A1 e A2, visto que pode ser difícil para o professor-avaliador compreender a evolução de sua turma);

11. Se possível, se aplica a prova a um colega ou a um nativo capacitado; se esses se encontram em dificuldade, o exercício ou o item em particular devem ser modificados ou substituídos;

12. É bom que aquele que prepara a prova possa revisála com antecedência antes de aplicá-la, podendo assim aperfeiçoar o conteúdo, a clareza, etc. (se trata de um processo de revisão análogo àquele que precede a escrita de um tipo qualquer de texto);

13. É preciso assegurar-se de que o local em que a prova será realizada seja adequado (não deve haver fontes de distração, deve ser suficientemente arejado, luminoso e espaçoso, etc.);

14. Terminada a prova, é recolhido o feedback dos alunos/ candidatos (eventualmente de forma anônima);

15. Os alunos devem ser alertados quanto às providências em caso de fraude, quais são as fontes permitidas (o 
dicionário?), se são previstas provas de recuperação reservadas aos ausentes;

16. Os alunos devem ser informados sobre como é computado o resultado final (é determinado pela média de outras provas? Contempla outros fatores, como a presença, a participação em sala, a entrega pontual das tarefas de casa, etc.?);

17. É bom que o professor guarde uma cópia da prova (para possíveis casos de contestação); ao aluno fica permitido fazer uma cópia da prova ou tirar uma foto da original;

18. É bom que cada exercício esteja munido de um exemplo;

19. As instruções devem ser simples e claras; é bom que quem aplique a prova se assegure de que os alunos a tenham compreendido (em uma turma monolíngue, se pode recorrer à L1 dos alunos);

20. É bom que o professor negocie com a turma a data da prova, de modo que essa não coincida com provas aplicadas por outros docentes;

21. É bom que, no momento da correção, o professor reveja cada resposta e que apresente sugestões para aqueles que precisam recuperar conteúdos com os quais têm maior dificuldade; 
22. É bom que o professor dê a nota/avaliação individualmente, sem expor para a classe, evitando assim confronto entre os alunos;

23. A prova deve ser corrigida e entregue em curto espaço de tempo; se o período for longo, o aluno pode ter dificuldade em lembrar das atividades e exercícios desenvolvidos;

\subsection{Recomendações específicas}

Relatamos abaixo recomendações que dizem respeito a testes separados, dependendo do assunto.

\subsubsection{Componentes linguísticos (léxico e morfologia)}

1. Podem-se prever itens iniciais com tamanho menor, rapidamente executáveis. Esses itens placebo - cujas respostas não é necessario levar em consideração na hora de computar a pontuação - eles visam promover uma percepção de auto-eficácia, ou seja, a sensação, por parte do candidato de conseguir finalizar a tarefa e poder assim conter sua ansiedade.

2. Cada exercício deve ser específico para cada componente (gramática e vocabulário não devem ser avaliados em um mesmo exercício ou, pior, através de um mesmo item);

3. É necessário prever um uso limitado e atento das imagens (considerando que nem sempre são claras);

4. É necessária uma certa proporção entre os exercícios, alocando mais espaço aos tópicos abordados mais profundamente; 
5. É necessário ter uma amostra suficiente de item: não muito extensos (um teste excessivamente longo pode gerar ansiedade e cansaço) ou muito reduzido (em um teste de proficiência, em particular, o número deve respeitar os requisitos de confiabilidade);

6. Cada item ou o texto inteiro no qual o teste é realizado (por exemplo, um cloze morfossintático) deve ser acessível ao máximo em termos de entendimento;

7. Em testes gramaticais de múltipla escolha, é recomendável usar item de 4 opções;

8. Em provas que exigem a elicitação de formações complexas se pode considerar uma pontuação dupla (por exemplo, para um período composto, um ponto para o verbo auxiliar e um ponto para o particípio);

9. Nos testes gramaticais de múltipla escolha, cada opção deve cobrir a mesma categoria; veja um exemplo impróprio abaixo:

Giorgio lê o conto Maria.

- de

- entre

- a

- enquanto* 
10. Em provas gramaticais ou lexicais de múltipla escolha é bom evitar opções semanticamente impossíveis, que o aluno descarta imediatamente; veja o exemplo:

Giorgio e Silvia Maria.

- são*

- telefonam

- chamam

- escutam

11. Devem se evitar distratores generalizantes do tipo "nenhum destes"; "tudo isso", etc;

12. Nos testes de gramática, evite-se criar item com ocorrências pouco exploradas na sala de aula (por exemplo, os passados em uma turma de nível A2); em provas lexicais, os itens devem ser construídos para provocar ocorrências relativamente frequentes durante o caminho de aprendizagem.

\subsubsection{Provas relativas às habilidades}

A seguir, apresentamos recomendações relacionadas aos testes destinados a garantir a compreensão e produção.

\subsubsection{Habilidade de compreensão}

Compartilhamos uma série de sugestões sobre a escolha dos textos.

1. Textos que possam afetar a sensibilidade devem ser evitados (por exemplo, que abordem a guerra, violência, sexo, doença, etc.); 
2. Os textos devem ser calibrados com base na competência média da turma;

3. Textos absurdos, pouco coesos e coerentes, sem unidade temática devem ser evitados;

4. Textos pouco informativos (poucas ideias, repetitivos de várias maneiras) devem ser evitados;

5. Os textos não devem apresentar referências culturais pouco transparentes;

6. Textos de interesse do aluno e adequados à sua idade devem ser adotados;

7. Traduções de outras línguas devem ser evitadas;

8. Transposições diamésicas devem ser evitadas (textos escritos em forma oral ou o contrário, textos orais e transcritos);

9. Se a passagem for um extrato de um texto maior, devese prestar atenção para que nenhuma referência intertextual fornecida seja opaca (por exemplo, em uma entrevista pode ser opaca a menção, da parte do entrevistado, de detalhes relatados em uma notícia);

10. Textos com um contexto confuso devem ser evitados (por exemplo, uma passagem narrativa em que as relações entre os personagens não são claras); 
11. Qualquer manipulação na fonte deve ser mantida no mínimo, e em qualquer caso, ela deve ser monitorada (com colchetes, por exemplo, para a expulsão [...]) e a fonte deve ser informada;

12. Para áudio, é bom escolher textos nos quais o emissor assuma uma posição coerente consigo mesmo;

13. Para o áudio, as vozes devem ter um tom claro e uma pronúncia clara (sem vozes roucas, tons muito baixos, problemas de eloquência, variantes diatópicas às quais o aluno não foi exposto);

14. Para o áudio, textos de baixa qualidade devem ser descartados (não para músicas com zumbido, música de fundo muito alta, efeitos de distorção, etc.), qualquer que seja o nível;

15. Para textos escritos, aconselhamos que se abstenha de fornecer notas de rodapé como um glossário; se isso for necessário, quer dizer que o texto não é adequado;

16. Se os textos forem acompanhados de imagens, as imagens deverão ser altamente claras e não gerar dúvidas de interpretação;

Vamos seguir para controlar as práticas inerentes aos itens individuais.

17. Devem ser evitados itens preditivos, ou seja, os quais os alunos tenham maneira de responder sem que tenham 
necessidade de ter lido/escutado o texto. No exemplo abaixo, a resposta é evidente por si só:

O sol é:

um planeta

uma estrela

uma galáxia

18. Itens detalhados devem ser evitados (recomenda-se concisão, em particular, para testes de audição);

19. Ler os itens deve ser fácil (lembre-se que o entendimento dos itens não é avaliado, mas o entendimento do texto);

20. É bom garantir que os distratores sejam realmente falsos e não parcialmente verdadeiros. Da mesma forma, são evitados distratores absurdos (que não distraiam);

21. Tanto quanto possível, frases negativas devem ser evitadas, pois eles causam confusão;

22. Pela mesma razão, é melhor evitar categorias do tipo "informação não presente» ou «desconhecido», referente aos conteúdos transmitidos por um texto;

23. O reconhecimento lexical, ou seja, a recuperação direta, deve ser evitado, nas opções de partes do texto; é bom fazer uso de paráfrases ou sinônimos (acessíveis, em cada caso); 
24. Interdependência, isto é, a possibilidade de inferir a chave de um item de itens anteriores ou subsequentes;

25. Distratores contra-intuitivos devem ser evitados (falsos de acordo com o texto, mas verdadeiros na realidade das coisas);

26. Deve-se assegurar que a progressão dos itens respeite a progressão das informações presentes no texto (especialmente em testes de compreensão oral);

27. É necessário prever uma distribuição adequada das informações alvo (para a audição, é necessário evitar itens relacionados à informação muito perto ou muito distante; uma pausa muito longa pode induzir o ouvinte a se sentir perdido, com medo de ter perdido alguma coisa);

28. Os itens relacionados com a mesma informação devem ser evitados (o aluno pode ser penalizado ou recompensado duas vezes); mais geralmente, para atividades de audição, itens relacionados a um mesmo núcleo informativo devem ser evitados (o aluno não tem tempo de se concentrar no segundo item, pois ainda está empenhado na resolução do primeiro exercício)

29. Recomenda-se alguma uniformidade nas opções de escrita (deve ter mais ou menos o mesmo comprimento); 
30. Preferencialmente, é melhor evitar o uso de advérbios de frequência (sempre, nunca etc.) e pronomes indefinidos (ninguém, alguém, etc.), pois podem ser confusos;

31. Evite agrupar itens com informações redundantes, ou seja, repetidos em vários pontos do texto (os itens, neste caso, resultam desregulados);

32. As respostas aproximadas devem ser evitadas (a resposta deve corresponder perfeitamente com o conteúdo da informação alvo). Até mesmo os melhores alunos podem ser enganados por uma resposta imprecisa;

33. Deve-se evitar escrever opções contraditórias;

34. Deve-se construir item em passagens de difícil interpretação (ou, no caso específico da escuta, de difícil decodificação);

35. Distratores equivalentes devem ser evitados (isto é, que signifiquem mesma coisa);

36. No caso em que o item consiste em dois sintagmas (por exemplo, em uma pergunta de múltipla escolha, a combinação raiz + opção), verifique-se se não surgem problemas sintáticos internos ao enunciado. Pode acontecer, em provas preparadas por avaliadores descuidados, que isto se verifique em concordância com os distratores; 
37. Distratores externos ao texto devem ser evitados, pois isso pode confundir o candidato (o distrator deve estar sempre ancorado em informações presentes no texto, desmentindo-as);

38. Deve haver uma e apenas uma resposta;

39. É bom evitar respostas na forma de declarações coordenadas (por exemplo, "o mar era bonito e calmo "), em que um sintagma está correto, enquanto o outro não; neste caso, o item é indecidível;

40. Em um exercício de audição, itens muito grandes devem ser evitados, pois eles retêm o candidato, impedindo-o de acompanhar o áudio;

41. Para audição: os itens referentes à uma informação presentes nos primeiros segundos do texto (o candidato não tem o tempo de formular uma ideia acerca de qual seja o contexto no qual ocorre a situação comunicativa) e, desta maneira, devem ser evitados itens que se referem a uma informação presente nos últimos segundos da música (a qual pode escapar do candidato);

42. Para perguntas abertas relacionadas à leitura, recomenda-se indicar um limite para o número de palavras que compõem a resposta (caso contrário, teoricamente, um poderia reproduzir um parágrafo muito longo); 
Finalmente, algumas recomendações relacionadas à escolha das técnicas.

43. Depois de escolher um texto, é necessário se perguntar que técnica a ele se pode associar, por exemplo:

a. uma grade de compreensão (tabela para completar) é aplicável apenas a textos informativos densos, cujas informações podem ser facilmente esquematizadas e combinadas entre si;

b. um exercício de múltipla escolha é aplicável a textos informativamente densos;

c. uma reorganização de texto é acompanhada de textos marcados com uma consequência evidente (por exemplo, textos narrativos, biografias).

44. Num exercício de múltipla escolha, três opções são suficientes (a quarta é difícil de obter);

45. A arbitrariedade de verdadeiro ou falso pode ser limitada (dado que de cada item o aluno tem $50 \%$ de chance de adivinhar a resposta) recorrendo a um número considerável de item (o exercício é conhecido como 'individualização de informações') ou pedindo ao aluno que explique as razões de suas escolhas ("verdadeiro, por quê?"; "falso, por quê?", possivelmente em L1 ${ }^{4}$;

4 Cf. Mezzadri (2008). 
46. Existem formatos utilizados indevidamente para a detecção de habilidades de compreensão; é necessário evitar de utilizá-los: a tradução não é válida para avaliar a capacidade de compreensão oral (já que é uma habilidade integrada que prevê, também, exercícios da escrita);

O cloze (a menos que seja facilitado, as opções constituam distratores entre eles, que haja intrusos, e que remetam a um raciocínio semântico estendido) por si só não fornece uma fotografia confiável da capacidade de leitura;

O ditado (nas diferentes variantes) é uma prova inválida em referência às habilidades de compreensão oral;

47. Existem formatos pouco aceitos:

Exercícios de reorganização de texto longos e mecânicos não são bem-vindos (o os alunos mais velhos, em particular, não os apreciam);

Existem estudantes que, embora sejam linguisticamente competentes, são analfabetos na leitura de documentos com gráficos; é bom ter consciência disso.

Testes de compreensão com base na 'busca de erros' (ou seja, os detalhes incorretos em uma frase referente a uma parte de texto) podem não ser familiares à maioria;

A tabela de entrada dupla (a grade) também não é familiar a muitos (entre outras coisas, durante a fase de 
correção, é o momento para verificar a aceitabilidade de alguns complementos, se pode gerar perplexidade entre os avaliadores);

48. É bom utilizar vários tipos de técnicas, quando for possível, pois isso compensa os defeitos de cada uma.

\subsubsection{Habilidades de produção}

1. Adotem-se estímulos generativos que encorajem o aluno a falar/escrever (devem ser evitados estímulos que o aluno considere absurdos ou pouco justificados);

2. A prova deve ser calibrada no léxico e nas funções (não se pode pedir a um aluno do nível B1, por exemplo, para escrever uma revisão ou uma carta de protesto, uma vez que, ao fazê-lo, o colocaríamos em dificuldade);

3. A fim de incentivar diferentes sensibilidades, podem ser apresentadas atividades de redação qualificada, que exigem esforço igual (por exemplo, uma atividade criativa de escrita que atenda aos desejos expressivos dos mais divergentes, pode ser usado como alternativa a uma atividade de escrita funcional, centrada em necessidades concretas);

4. Ao aluno deve ser garantido tempo suficiente para produzir uma amostra representativa (ou seja, suficientemente grande) de sua capacidade;

5. Se possível, devem ser usadas grades analíticas ou, pelo menos, avalie-se analiticamente o desempenho (ou 
seja, se deve expressar um julgamento multidimensional, diferenciado de acordo com as categorias de que se compõe a oração de referência; por exemplo, para parte escrita se atribua uma nota à gramática e ortografia, uma ao léxico, uma à organização do texto e uma à eficácia);

6. Na competência oral, é bom manter contato visual com o(s) aluno(s); se evita-se, a autenticidade da comunicação pode falhar;

7. Na competência oral, por razões de segurança, é bom prever uma variedade de tarefas que se podem utilizar (se tivermos um pequeno conjunto de perguntas, por exemplo, os alunos que são entrevistados por último são facilitados, pois podem ser informados pelos primeiros sobre o que consiste a entrevista);

8. Na competência oral, se possível, é bom contar com o apoio de um colega: um dos dois desempenha o papel de interlocutor, o outro avalia o desempenho;

9. Na escrita, se são usadas escritas guiadas (na forma de lista com marcadores), se deve garantir que a progressão dos pontos favoreça uma redação de um texto coerente;

10. Na escrita, deve ser estabelecido um número mínimo (e possivelmente máximo) de palavras;

11. A avaliação deve ser respeitosa (não deve fazer referência à pessoa, mas ao desempenho), detalhado (não 
genérico) e útil para quem o recebe (o aluno precisa saber o que realmente reforçar e como fazer isso);

12. Se o aluno parar durante a fala, ele deve ser instigado a retomar a discussão, por meio de frases de apoio;

13. Para a fala, são esperados testes de interação desde os níveis mais baixos;

14. Se o aluno é obrigado a fazer uma apresentação oral suportado por slides ou outros dispositivos, é necessário esclarecer o que é esperado (por exemplo, que não leia o texto, exceto frases curtas, que olhe nos olhos os colegas, que respeite o tempo estipulado). Ao mesmo tempo tem que ser inibidos, com a devida assertividade, comportamentos passivos nos ouvintes, considerando que, na perspectiva do apresentador, ter na sua frente um público que não mostra interesse inibe o desejo de se comunicar.

\section{CONCLUSÃO}

Através deste ensaio, pretendemos apresentar procedimentos de controle que contribuam para a validade de uma prova. Compartilhar as boas práticas de item writing é um requisito técnico e, ao mesmo tempo, ético, uma vez que o julgamento dirigido ao aluno tem consequências imediatas na percepção de que ele tem sua própria competência e, portanto, de sua autoestima, de sua motivação e de seu compromisso. A avaliação linguística é uma operação muito 
delicada. Em suma, se realizada com superficialidade, pode repentinamente tomar inúteis todas as precauções feitas pelo professor, na sala de aula, para tornar o aprendizado de idiomas dinâmico e envolvente. Por outro lado, quanto maior o cuidado e a prudência em estabelecer uma prova, pelo professor e/ou avaliador, mais fiel e respeitosa será a "fotografia" que eles serão capazes de assumir sobre a competência do aluno.

\section{REFERÊNCIAS}

ALDERSON, J. C.; CLAPHAM C.; WALL D. (1995). Language Test Construction and Evaluation. CUP, Cambridge.

CANGELOSI, J. S. (1990). Designing Tests for Evaluating Student Achievement. Longman, White Plains: New York.

GREEN, R. (2017). Designing Listening Tests. Palgrave: London.

HALADYNA, T. M.; DOWNING, S. M.; RODRIGUEZ M. C., A. (2002). "Review of Multiple-choice Item-Writing Guidelines for Classroom Assessment". In Applied Measurement in Education. p.309-334.

KINTSCH, W.; YARBROUGH, J. C. (1982). "Role of Rhetorical Structure in Text Comprehension". Journal of Educational Psychology. p.828-834.

MEZZADRI, M. (2008). Insegnare a comprendere. Guerra: Perugia.

NOVELLO A. (2015). Testare l'ascolto: l'abilità e linee guida per la costruzione di item. Officina.it.

PURPURA, A. (2004). Assessing Grammar. CUP: Cambridge.

ROCCA, L. (2016). "Controllo, verifica e valutazione". In: A. Borri; F. Minuz; L. Rocca (Eds.). Progettare percorsi di L2 per adulti stranieri. Dall'alfabetizzazione all'A1. Loescher, Torino.

SCHEDL, M.; MALLOY, J. (2014). "Writing Items and Tasks". In: A. J. Kunnan (Ed.). The Companion to Language Assessment. John Wiley and Sons, New Jersey. p.1-18. 
SERRAGIOTTO, G. (2016). La valutazione degli apprendimenti linguistici. Loescher, Torino.

TORRESAN, Paolo (2015a). Studio su cloze mirati della certificazione CILS, livello avanzato. Dialogarts, Rio de Janeiro.

(2015b). "Analisi (classica, Rasch, dei distrattori) di una prova di lettura a scelta multipla della certificazione di italiano per stranieri CILS". Euro-American Journal of Applied Linguistics and Languages. 2(1), p.2055.

Paolo Torresan é italiano de Treviso, cidade ao Norte da Itália. Desenvolveu os seus estudos na Università Ca' Foscari, em Veneza, graduando-se em Filosofia (1999). Mestre em Didática e Promoção da Língua Italiana (2002) e Doutor em Linguística e Filologia Românica (2006). Foi estudante visitante na Universidad Complutense e Autônoma de Madrid (Espanha); Pesquisador visitante no Santa Monica College (USA) e na Lancaster University (Inglaterra). Ministrou cursos na Università di Verona e na Università di Catania (Itália). Sua experiência de trabalho concentra-se na formação de docentes de Italiano em Língua Estrangeira. De 2010 a 2011 foi Professor Visitante na Universidade do Estado do Rio de Janeiro. Atualmente é professor Adjunto na Universidade Federal Fluminense (Niterói). 